\title{
BRONGNIARTIA HERBACEA (LEGUMINOSAE, PAPILIONOIDEAE), UNA ESPECIE NUEVA DE MICHOACÁN, MÉXICO
}

\author{
Rosaura Grether ${ }^{1,3}$ y Jerzy Rzedowski ${ }^{2}$ \\ ${ }^{1}$ Universidad Autónoma Metropolitana-Iztapalapa, División CBS, Departamento de \\ Biología, Apdo. postal 55-535, 09340 México, D.F. México. \\ ${ }^{2}$ Instituto de Ecología, A.C., Centro Regional del Bajío, Apdo. postal 386, \\ 61600 Pátzcuaro, Michoacán, México. \\ 33Autor para la correspondencia: rogg@xanum.uam.mx
}

\section{RESUMEN}

Se describe e ilustra Brongniartia herbacea, un taxon nuevo, endémico del norte de Michoacán. Se relaciona con el grupo de especies ubicado alrededor de B. podalyrioides Kunth y B. inconstans S. Watson.

Palabras clave: Brongniartia, hierbas, endemismo, Leguminosae, Flora del Bajío, México.

\section{ABSTRACT}

Brongniartia herbacea, a new taxon, endemic to northern Michoacán, is described and illustrated. It is related to the species of the B. podalyrioides Kunth and B. inconstans S. Watson group.

Key words: Brongniartia, herbs, endemism, Leguminosae, Flora of the Bajío, Mexico.

Bajo el nombre genérico de Brongniartia se agrupan poco más de 50 especies, casi todas restringidas en su distribución a los límites de nuestro país, por lo que el conjunto debe considerarse como particularmente propio y característico de la flora mexicana. Estas plantas son comunes sobre todo en la vertiente pacífica, donde muchas forman parte del bosque tropical caducifolio y de las comunidades secundarias derivadas del mismo. 
En su mayoría se registran como arbustos con flores moderadamente grandes, de color morado, rosado, rojizo, amarillo y azul; algunos alcanzan la talla de pequeños árboles. Más de la tercera parte de los representantes conocidos de este grupo son microendemismos, encontrados solo en la localidad tipo y a veces en sitios inmediatamente contiguos. La especie que a continuación se describe también aparenta ser de la misma categoría y en adición, es la única en el género de porte francamente herbáceo.

Brongniartia herbacea R. Grether \& Rzed., sp. nov. Fig. 1.

Planta herbacea ad $30 \mathrm{~cm}$ alta; caules dense pilosi; stipulae oblique ovatodeltoideae 8-14 mm longae, plerumque glabrae sed marginibus pilosis; foliola (5-)79(-11) elliptica vel ovata (4-)6-13 mm longa, (2-)3-8 mm lata, plerumque glabra sed marginibus pilosis, membranacea; flores plerumque solitarii axillares saepe in catervis racemiformibus foliosis aggregati; calyx fere glaber 7-11 mm longus; corolla atrorubra vel purpurea 14-16.5 mm longa; fructus maturus ignotus.

Planta herbácea perenne, erecta; raíz principal algo leñosa, hasta de $6 \mathrm{~mm}$ de diámetro; tallos varios partiendo de la base, algunos algo leñosos y ramificados en la parte proximal, hasta de $30 \mathrm{~cm}$ de alto, densamente pilosos con pelos patentes de 1 a 2 mm de largo, amarillentos; hojas imparipinnadas, estípulas oblicuamente ovadodeltoides a ligeramente cordiformes, de $8 \mathrm{a} 14 \mathrm{~mm}$ de largo, de 6 a $13 \mathrm{~mm}$ de ancho, agudas en el ápice, truncadas y oblicuamente cordadas en la base, palmadamente 5-7-nervadas, glabras en ambas superficies, rara vez esparcidamente pilosas en el envés, el margen densamente piloso, pecíolo delgado, de (9)11 a $13 \mathrm{~mm}$ de largo, raquis de (7)11 a $31 \mathrm{~mm}$ de largo, estipelas de 1 a $1.5 \mathrm{~mm}$ de largo, setáceas, pilosas, folíolos (5)7 a 9(11), los laterales opuestos, elípticos a ovados, a veces casi orbiculares, de (4)6 a 9(10) mm de largo, de (2)3 a 6 mm de ancho, el folíolo terminal de 8 a $13 \mathrm{~mm}$ de largo, de 6 a $8 \mathrm{~mm}$ de ancho, agudos a redondeados y mucronulados en el ápice, redondeados a truncados en la base, con venación reticulada prominente en el envés, glabros en ambas superficies, rara vez esparcidamente pilosos en el envés, el margen densamente piloso, de textura membranácea, peciólulos de ca. $1 \mathrm{~mm}$ de largo; flores generalmente solitarias, rara vez dos, en las axilas de las hojas superiores, a menudo llegando a formar ramas racemiformes con las hojas (al menos en la antesis) diminutas en sus porciones terminales, pedúnculos de 6 a $10 \mathrm{~mm}$ de largo, glabros, brácteas triangulares, de 1.5 a $2 \mathrm{~mm}$ de largo, parcialmente envolventes en la base, con un mechón de pelos en el ápice, bractéolas ausentes; hipantio obcónico, de 2.5 a 4 mm de largo, de 2 a 4 mm de ancho, glabro, cáliz anchamente campanulado, marcescente, 
Grether y Rzedowski: Brongniartia herbacea, especie nueva de Michoacán, México

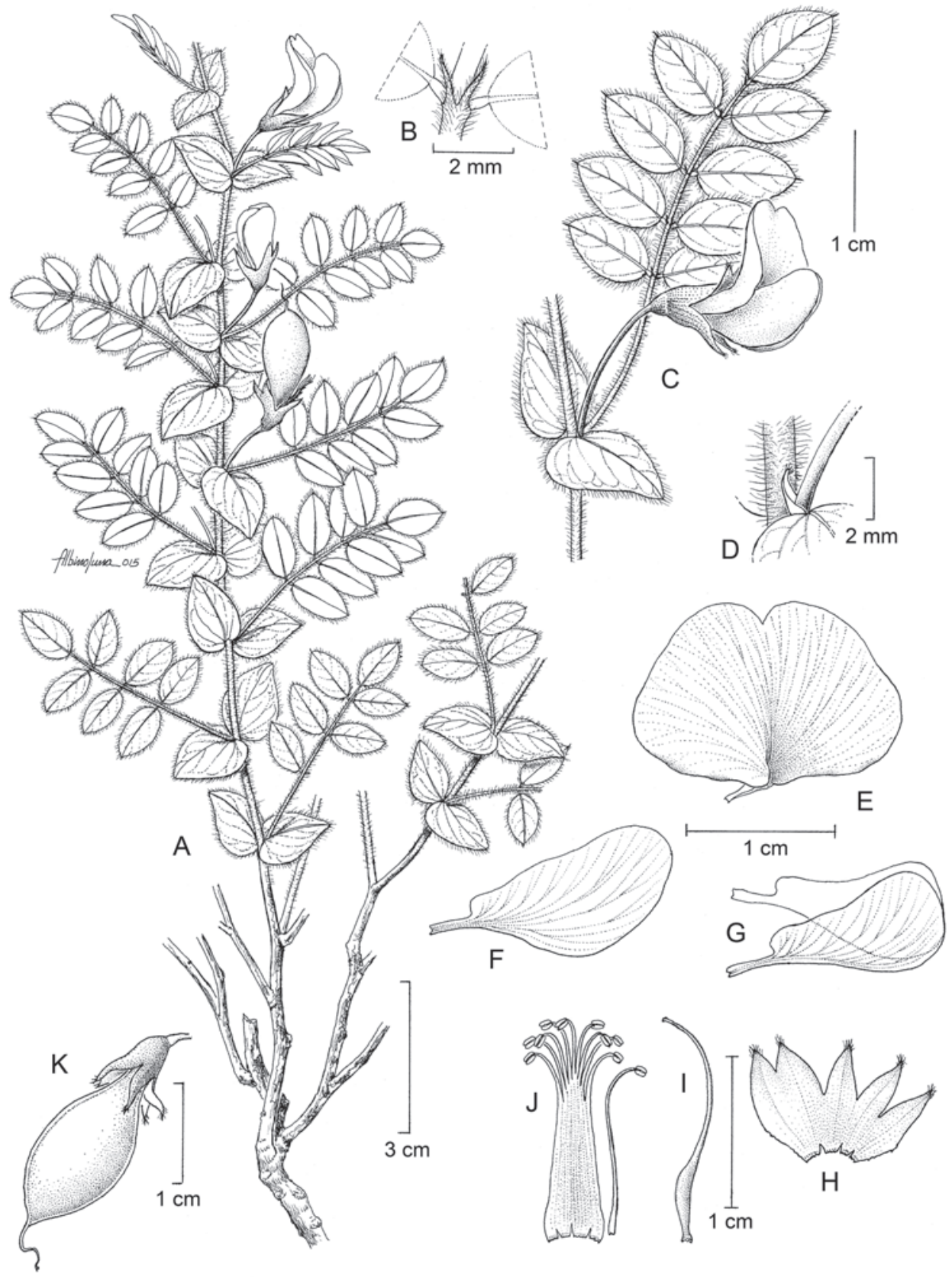

Fig.1. Brongniartia herbacea R. Grether \& Rzed. A. porte de la planta; B. estipelas; C. flor, estípulas foliosas y hoja; D. bráctea floral; E. estandarte; F. ala; G. quilla; H. cáliz; I. gineceo; J. androceo; K. fruto tierno. Ilustrado por Albino Luna. 
de 7 a $11 \mathrm{~mm}$ de largo, tubo de 2.5 a $4 \mathrm{~mm}$ de largo del lado abaxial, de 5.5 a $6.5 \mathrm{~mm}$ del lado adaxial, los dientes abaxiales de 4.5 a $7 \mathrm{~mm}$ de largo, los adaxiales de 2 a 2.5 mm de largo, todo el cáliz glabro externamente, excepto el ápice de algunos dientes con un mechón de pelos cortos; corola rojo oscuro a morada, estandarte suborbicular o muy anchamente ovado, con una mancha amarilla en el centro, en la antesis formando un ángulo de $90^{\circ}$ respecto al pedúnculo floral, de 12 a $14 \mathrm{~mm}$ de largo y de 15 a $18 \mathrm{~mm}$ de ancho, emarginado en el ápice, truncado en la base, la uña de 2 a $2.5 \mathrm{~mm}$ de largo, alas oblicuamente elípticas, de 11 a $14 \mathrm{~mm}$ de largo, de 7 a $8.5 \mathrm{~mm}$ de ancho, la uña de 2.5 a $3 \mathrm{~mm}$ de largo, auriculadas del lado interno, los pétalos de la quilla oblicuamente obovados, de 10 a $12 \mathrm{~mm}$ de largo, de 6.5 a $7 \mathrm{~mm}$ de ancho, fusionados en la porción superior y libres en el ápice y en la base, la uña de 2.5 a 3.5 mm de largo, auriculados del lado interno; androceo de 15 a $17.5 \mathrm{~mm}$ de largo, glabro, el tubo de 9 a $11 \mathrm{~mm}$ de largo, la parte libre de los filamentos de 6 a $6.5 \mathrm{~mm}$ de largo, el estambre libre de 12 a $13 \mathrm{~mm}$ de largo, anteras oblongas, de 1 a $1.5 \mathrm{~mm}$ de largo; ovario de 4 a $5.5 \mathrm{~mm}$ de largo y $1 \mathrm{~mm}$ de ancho, glabro, estipitado, estípite de ca. $1.5 \mathrm{~mm}$ de largo, estilo de ca. $9 \mathrm{~mm}$ de largo, glabro, estigma capitelado; fruto maduro desconocido, fruto tierno cortamente estipitado, cuerpo angostamente obovado, de 17 a $20 \mathrm{~mm}$ de largo y de 8 a 9 mm de ancho, aplanado dorsoventralmente, glabro, sin ala.

Holotipo: MÉXICO. Michoacán, municipio de La Piedad, El Jagüey, alt. 1700 m, matorral subtropical perturbado, 7.VII.1990, E. Pérez Calix y E. García López 1420 (IEB, isotipos por distribuirse).

La especie se conoce sólo de la localidad tipo, donde se registra como abundante.

En virtud de sus flores que se agrupan en ramas racemiformes, así como de sus estípulas anchas, $B$. herbacea señala relaciones con el grupo de especies ubicado alrededor de B. podalyrioides Kunth y B. inconstans S. Watson.

Para la Flora Novo-Galiciana, McVaugh (1987, pp. 306-307) reconoció a B. inconstans como arbusto glabro, con estípulas hasta de $6 \mathrm{~cm}$ de largo y folíolos de 3 a $7 \mathrm{~cm}$ de largo, follaje coriáceo y flores de 2.3 a $2.5 \mathrm{~cm}$ de largo, pero en un apéndice definió la existencia en Jalisco y en la parte meridional de Zacatecas, de "poblaciones aberrantes” de la misma especie, que son plantas herbáceas a subarbustivas de 0.5 a $1 \mathrm{~m}$ de alto, con pelos de 1 a $2 \mathrm{~mm}$ de largo, folíolos 3 o a veces 5, de 0.8 a 3.7 cm de largo, estípulas de 1 a 3(5) cm de largo, cáliz de 13 a 18 mm de largo, corola de 2.3 a $2.5 \mathrm{~cm}$ de largo.

Posteriormente, Dorado $(1989,1992)$ se abocó a una revisión taxonómica del grupo “podalyrioides” de Brongniartia y decidió ubicar las mencionadas plantas de Zacatecas como una subespecie de B. inconstans. Sin embargo, al parecer no llegó a publicarse formalmente tal taxon. 
Estas “poblaciones aberrantes” (o la subespecie inédita) son las que se relacionan más con $B$. herbacea, como se muestra en el Cuadro 1 , pero esta última ya se diferencia tanto de $B$. inconstans típica, que no procedería considerarlas como conespecíficas.

La especie nueva formará parte del fascículo Leguminosae-Papilionoideae I de la Flora del Bajío y de regiones adyacentes. Se diferencia de las cuatro restantes (B. parryi Hemsl., B. lupinoides (Kunth) Taub., B. foliolosa Benth. ex Hemsl. y B. magnibracteata Schltdl., en su hábito herbáceo, en sus estípulas muy anchas y en sus flores agrupadas en ramas racemiformes.

Cuadro 1. Caracteres comparativos entre Brongniartia herbacea y poblaciones "aberrantes" y típicas de B. inconstans.*

\begin{tabular}{|c|c|c|c|}
\hline & B. herbacea & $\begin{array}{l}\text { B. inconstans } \\
\text { "aberrantes" }\end{array}$ & B. inconstans típicas \\
\hline Hábito & hierba perenne & $\begin{array}{l}\text { hierba leñosa en la } \\
\text { base o sufrutescente }\end{array}$ & arbusto \\
\hline $\begin{array}{l}\text { Tamaño de la } \\
\text { planta }\end{array}$ & $\begin{array}{l}\text { hasta de } 30 \mathrm{~cm} \text { de } \\
\text { alto }\end{array}$ & de 0.5 a $1 \mathrm{~m}$ de alto & $\begin{array}{l}\text { de }(0.5) 1 \text { a } 1.5 \mathrm{~m} \text { de } \\
\text { alto }\end{array}$ \\
\hline $\begin{array}{l}\text { Indumento de las } \\
\text { ramas }\end{array}$ & $\begin{array}{l}\text { pilosas, con pelos de } \\
1 \text { a } 2 \mathrm{~mm} \text { de largo }\end{array}$ & $\begin{array}{l}\text { pilosas con pelos de } 1 \text { a } \\
2 \mathrm{~mm} \text { de largo }\end{array}$ & glabras \\
\hline \multicolumn{4}{|l|}{ Estípulas } \\
\hline tamaño & $8-14$ x 6-13 mm & $\begin{array}{l}(10) 15-30(50) \times(7) 11- \\
15(45) \mathrm{mm}\end{array}$ & $24-60$ x 18-43 mm \\
\hline indumento & $\begin{array}{l}\text { glabras en ambas } \\
\text { superficies, rara vez } \\
\text { levemente pilosas en } \\
\text { el envés, el margen } \\
\text { densamente piloso }\end{array}$ & $\begin{array}{l}\text { pilosas en el envés y en } \\
\text { el margen }\end{array}$ & $\begin{array}{l}\text { glabras en ambas } \\
\text { superficies y en el } \\
\text { margen }\end{array}$ \\
\hline \multicolumn{4}{|l|}{ Folíolos } \\
\hline número & $(5) 7-9(11)$ & $\begin{array}{l}\text { 3(5) [sólo } 1 \text { hoja } \\
\text { observada con 7] }\end{array}$ & $1-3(7)$ \\
\hline tamaño & (4)6-13 x (2)3-8 mm & $\begin{array}{l}(8) 24-37 \times(5) 8-25 \\
m m\end{array}$ & $30-70$ x 15-50 mm \\
\hline textura & membranácea & coriácea & coriácea \\
\hline indumento & $\begin{array}{l}\text { glabros en ambas } \\
\text { superficies, rara vez } \\
\text { levemente pilosos en } \\
\text { el envés, el margen } \\
\text { densamente piloso }\end{array}$ & $\begin{array}{l}\text { haz glabro, envés } \\
\text { esparcidamente piloso, } \\
\text { el margen densamente } \\
\text { piloso }\end{array}$ & $\begin{array}{l}\text { glabros en ambas } \\
\text { superficies y en el } \\
\text { margen }\end{array}$ \\
\hline
\end{tabular}


Cuadro 1. Continuación.

\begin{tabular}{|c|c|c|c|}
\hline & B. herbacea & $\begin{array}{l}\text { B. inconstans } \\
\text { "aberrantes" }\end{array}$ & B. inconstans típicas \\
\hline \multicolumn{4}{|l|}{ Cáliz } \\
\hline indumento & $\begin{array}{l}\text { glabro, algunos } \\
\text { dientes con mechón } \\
\text { apical de pelos }\end{array}$ & $\begin{array}{l}\text { piloso, los dientes } \\
\text { pilosos hasta la base } \\
\text { o con mechón apical } \\
\text { de pelos o a veces } \\
\text { totalmente glabro }\end{array}$ & $\begin{array}{l}\text { glabro, los dientes } \\
\text { sin mechón apical de } \\
\text { pelos }\end{array}$ \\
\hline \multicolumn{4}{|l|}{ Estandarte } \\
\hline tamaño de lámina & $12-14 \times 15-18 \mathrm{~mm}$ & similar al de las típicas & $23-27$ x 20-25 mm \\
\hline uña & $2-2.5 \mathrm{~mm}$ & similar al de las típicas & $3 \mathrm{~mm}$ \\
\hline \multicolumn{4}{|l|}{ Alas } \\
\hline tamaño de lámina & $11-14$ x 7-8.5 mm & similar al de las típicas & $20 \times 9-10 \mathrm{~mm}$ \\
\hline uña & $2.5-3 \mathrm{~mm}$ & similar al de las típicas & $2.5 \mathrm{~mm}$ \\
\hline \multicolumn{4}{|l|}{ Quilla } \\
\hline tamaño de pétalos & $10-12 \times 6.5-7 \mathrm{~mm}$ & similar al de las típicas & $16-22$ x 8-10 mm \\
\hline uña & $2.5-3.5 \mathrm{~mm}$ & similar al de las típicas & $3-5 \mathrm{~mm}$ \\
\hline \multicolumn{4}{|l|}{ Androceo } \\
\hline longitud & $15-17.5 \mathrm{~mm}$ & similar al de las típicas & ca. $20 \mathrm{~mm}$ \\
\hline
\end{tabular}

*Los ejemplares examinados de las poblaciones “aberrantes” y las poblaciones típicas de $B$. inconstans se presentan en el Apéndice.

\section{AGRADECIMIENTOS}

Los autores desean manifestar su reconocimiento al Sr. Albino Luna por la excelente ilustración de la especie. Rzedowski agradece el apoyo recibido de parte de la Comisión Nacional para el Conocimiento y Uso de la Biodiversidad.

\section{LITERATURA CITADA}

Dorado, O. 1989. A morphological revision of the podalyrioides group of Brongniartia (Fabaceae: Faboideae). Master of Arts dissertation. Claremont Graduate School. Claremont, USA. 316 pp. 
Dorado, O. 1992. A systematic and evolutionary study of the genus Brongniartia (Fabaceae). Ph.D. dissertation. Claremont Graduate School. Claremont, USA. 160 pp.

McVaugh, R. 1987. Brongniartia. Flora Novo-Galiciana 5: 297-321. 


\section{APÉNDICE}

Ejemplares selectos de Brongniartia inconstans usados para la comparación morfológica con B. herbacea.

A) poblaciones “aberrantes":

MÉXICO. Jalisco: road between Colotlán and Bolaños, 7-9.IX.1897, J. N. Rose 2843 (MEXU). Zacatecas: 5 miles SW of Jalpa, 30.VIII.1960, R. McVaugh 18502 (MEXU); Mpio. Moyahua, cerro La Cantarilla, a 8.5 km S de Moyahua, por la carretera México 54, tramo Moyahua-Ixtlahuacán del Río, 5.VII.1996, E. D. Enríquez et al. 936 (MEXU); Mpio. Juchipila, Apozol, 20 km N de Juchipila, 1400 m, 16.VIII.1984, R. Hernández-Magaña et al. 9640 (MEXU).

B) poblaciones típicas:

MÉXICO. Jalisco: hillsides about Tequila, 2.VII.1893, C. G. Pringle 4415 (MEXU); 2 miles NW of Tequila, 1200 m, 3.IX.1960, R. McVaugh 18631 (MEXU); Mpio. Tequila, Lo de Teresa, 8 km O de Tequila, 1400 m, 12.VIII.1984, R. Hernández-Magaña et al. 9560 (MEXU). 